\title{
Artritis séptica de la sínfisis del pubis
}

\author{
Rodrigo Mardones $\mathbf{P}^{1,2}$, Claudio Rojas $\mathrm{Pa}^{\mathrm{a}}$, \\ Maximiliano Carmona $\mathrm{C}^{\mathrm{a}}$. \\ Pubic symphysis septic arthritis. \\ Report of one case
}

\begin{abstract}
Septic arthritis of the pubic symphysis is an unusual disease. Its clinical presentation includes pubic pain, fever and alteration of serum inflammatory markers in most cases. We report a 23 year-old male presenting with pubic pain and fever. Magnetic resonance showed an arthritis of the pubic symphysis and a $18 \times 8 \mathrm{~mm}$ liquid collection. The patient was treated with antibiotics with a good clinical response. Two weeks after discharge, he was completely asymptomatic (Rev Méd Chile 2007; 135: 1040-3).
\end{abstract}

(Key words: Anti-bacterial agents; Arthritis, infections; Pubic Symphysis)

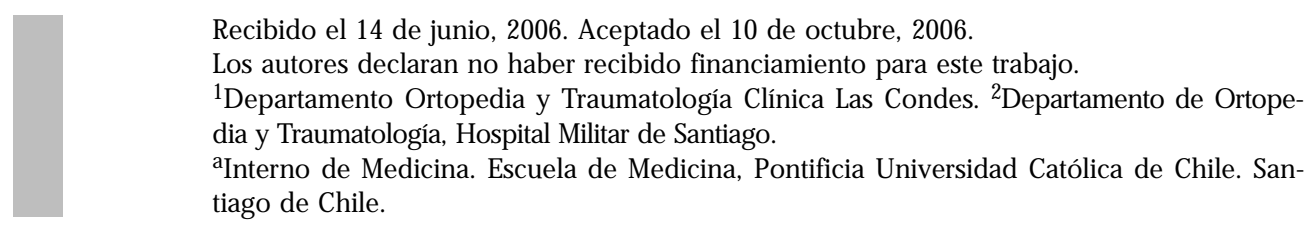

L

a artritis séptica de la sínfisis del pubis (ASSP)

es una patología infrecuente, de difícil diagnóstico, que se presenta clínicamente con dolor púbico irradiado a zona inguinal, muslo o glúteo, pudiéndose presentar marcha antiálgica y fiebre. Dentro de los exámenes de laboratorio, se observa alza de los parámetros inflamatorios en forma variable, siendo la VHS y PCR los que con mayor frecuencia se alteran. Los exámenes de imagen son de gran utilidad para realizar el diagnóstico, destacando la resonancia magnética $(\mathrm{RM})$ y la tomografía computada (TC) por sobre el resto.

Existen múltiples diagnósticos diferenciales, destacando la osteítis púbica, cuya presentación clínica puede ser difícil de diferenciar, requiriéndose de una alta sospecha para realizar el diagnóstico de ASSP. La incidencia de la ASSP, hasta el conocimiento de los autores, no está descrita en la literatura. La información disponible está compuesta principalmente por reportes de casos. En el

Correspondencia a: Dr. Rodrigo Mardones Departamento de Traumatología Clínica Las Condes. Lo Fontecilla 441, Las Condes. Fono: 02-4888244. Fax: 02-4888229. E mail: mardones@clc.cl siguiente trabajo presentamos un caso de ASSP y una discusión en base a la literatura.

\section{CASO CĹNICO}

Paciente de sexo masculino de 23 años, consultó por un cuadro de un día de evolución de dolor hipogástrico y en zona pubiana, asociado a compromiso del estado general y sensación febril. Dentro de sus antecedentes médicos, destacaba un asma intermitente en tratamiento con salbutamol según necesidad. Al ingreso el paciente relató un antecedente de uretritis que posteriormente negó.

En la evaluación inicial destacaba fiebre hasta $37,9^{\circ} \mathrm{C}, \mathrm{FC} 80$ por minuto y PA $180 / 76 \mathrm{mmHg}$. En el examen físico, el paciente presentaba un examen pulmonar normal, a la auscultación cardiaca un soplo sistólico II/VI en foco aórtico. El abdomen era blando, depresible y sensible a la palpación en hipogastrio. En la sínfisis púbica y zona inguinal derecha destacaba dolor importante a la palpación. Se palpaban adenopatías inguinales bilaterales, no dolorosas. Dentro de los exámenes de laboratorio 
destacaba, en el hemograma, leucocitos de 12.000 $\mathrm{x} \mathrm{ml}$, con $4 \%$ de baciliformes y una PCR de 45,47 $\mathrm{mg} / \mathrm{dl}$ (rango normal 0,1-5,0 mg/dl).

La radiografía de pelvis AP mostró, a nivel de la sínfisis púbica, una discreta esclerosis subcondral con mínima irregularidad del margen cortical inferior, algo mayor a derecha (Figura 1). Se inició tratamiento antibiótico con cloxacilina $1 \mathrm{~g}$ cada 6 $\mathrm{h}$ endovenoso con el diagnóstico de ASSP. El paciente evolucionó febril, con marcado compromiso del estado general y aparición de un síndrome ictérico secundario a su sepsis, por lo que se decidió trasladar a nuestro centro al tercer día de iniciado el tratamiento.

El paciente fue ingresado febril, hasta $38,4^{\circ} \mathrm{C}$, hemodinámicamente estable. Al examen físico destacaba dolor intenso a la palpación de la sínfisis del pubis, con un examen de cadera, columna y neurológico normales. El laboratorio mostró un recuento de blancos normal, con $16 \%$ de baciliformes, una PCR de 23,2 mg/dl (rango normal $0,1-1,0 \mathrm{mg} / \mathrm{dl}$ ) y una alteración de pruebas hepáticas con un patrón colestásico: SGOT de 42 UI/L (10-40), SGPT de 48 UI/L (10-55), bilirrubina total de $3,29 \mathrm{mg} / \mathrm{dl}(0-1)$, bilimubina directa de $1,85 \mathrm{mg} / \mathrm{dl}(0-0,2)$, GGT de $127 \mathrm{UI} / \mathrm{L}$ (4-50), FA de $228 \mathrm{UI} / \mathrm{L}(45-115)$ e INR de 1,3. Se tomaron 2 hemocultivos que resultaron negativos. La RM mostró hallazgos compatibles con una artritis de la sínfisis del pubis, con cambios inflamatorios del obturador externo en forma bilateral, mayor a derecha, en el cual se observa además, una colección de 18 x $8 \mathrm{~mm}$ (Figuras 2 y 3).

Se realizó TC de abdomen para descartar colecciones hepáticas, el cual no mostró hallazgos patológicos y TC de pelvis, que sólo mostró erosión ósea a nivel de sínfisis púbica.

Se inició tratamiento antibiótico con cefazolina $1 \mathrm{~g}$ cada $8 \mathrm{~h}$ endovenoso y clindamicina $600 \mathrm{mg}$ cada $8 \mathrm{~h}$ endovenoso con buena respuesta clínica y de laboratorio, resolviéndose su cuadro agudo, sin requerir tratamiento quirúrgico.

Junto al equipo de radiología de nuestro centro, se consideró que la colección no era del tamaño suficiente para asegurar la efectividad de la punción y, dada la buena respuesta del paciente al tratamiento antibiótico empírico, se decidió no insistir en la identificación del agente causal.

Paciente controlado de forma ambulatoria a las dos semanas de tratamiento antibiótico, encontrándose en buenas condiciones generales con resolución total de los síntomas.

\section{Discusión}

La sínfisis del pubis es una articulación que se ubica entre los cuerpos de los huesos púbicos. Cada cara articular del pubis está cubierta por una capa delgada de cartílago hialino, unido al cartíla-

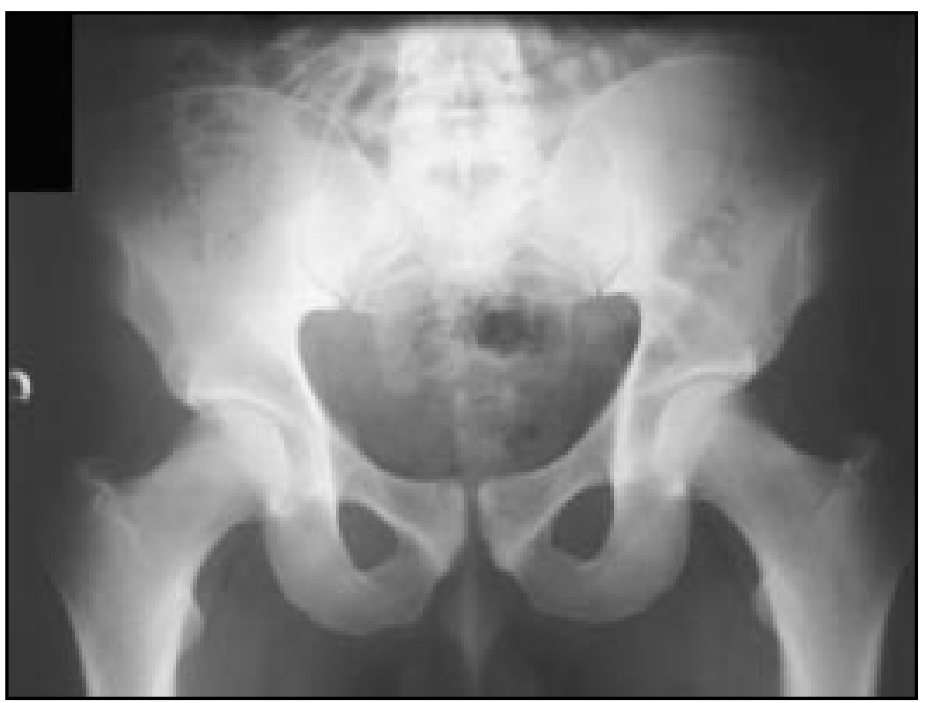

Figura 1. Radiografía de pelvis AP, que muestra irregularidad del margen cortical inferior de la sínfisis. 
go del lado opuesto por un grueso disco fibrocartilaginoso interpúbico, el cual está reforzado por los ligamentos pubiano superior y arqueado ${ }^{1}$.

La inflamación y la infección del pubis son condiciones patológicas infrecuentes, que clínicamente son difíciles de diferenciar, utilizándose los términos osteítis púbica y osteomielitis del pubis, respectivamente ${ }^{2}$. Cuando la infección compromete a la sínfisis púbica se conoce como artritis séptica de la sínfisis púbica.

La osteítis púbica es un término utilizado para describir una condición benigna $\mathrm{y}$ autolimitada que afecta al pubis, de etiopatogenia aún incierta ${ }^{2}$. Se caracteriza por cuadros de dolor pélvico, específicamente en la ingle, que aumenta con la deambulación y la abducción de la cadera, pudiendo presentar incluso fiebre leve en algunos casos. No se asocia a un cuadro infeccioso y se presenta con cultivos siempre negativos, siendo esta característica lo que la diferencia de la osteomielitis del pubis. Se asocia a etiologías como trauma, periodo posparto, atletismo y procedimientos quirúrgicos del sistema digestivo, urológico y genital. Responde de excelente forma al tratamiento con AINES o corticoides ${ }^{2-7}$.

La osteomielitis pélvica corresponde a menos de $10 \%$ de todas las osteomielitis, dentro de éstas el compromiso del pubis es extremadamente $\mathrm{raro}^{8}$. No se encontró datos en la literatura de incidencia de ASSP.

Ross et $\mathrm{al}^{9}$, en una revisión de 100 casos determinaron los principales factores de riesgo para ASSP, los cuales se especifican en la Tabla 1.

El agente etiológico más frecuentemente identificado fue el Estafilococo aureus $34 \%{ }^{9}$, seguido por Pseudomonas aeruginosa y causas polimicrobianas, sin embargo, esto último vanía según los factores de riesgo del paciente ${ }^{9}$. Existe consenso en la actualidad que la punción articular es un elemento fundamental en la evaluación de una monoartritis séptica ${ }^{10}$. En relación a la punción de las colecciones identificadas durante el desarmollo de una ASSP, no encontramos indicaciones absolutas de ésta. Se ha reportado necesidad de punción de articulación sacroilíaca cuando la colección es mayor a $5 \mathrm{~cm}$. Wamer reportó

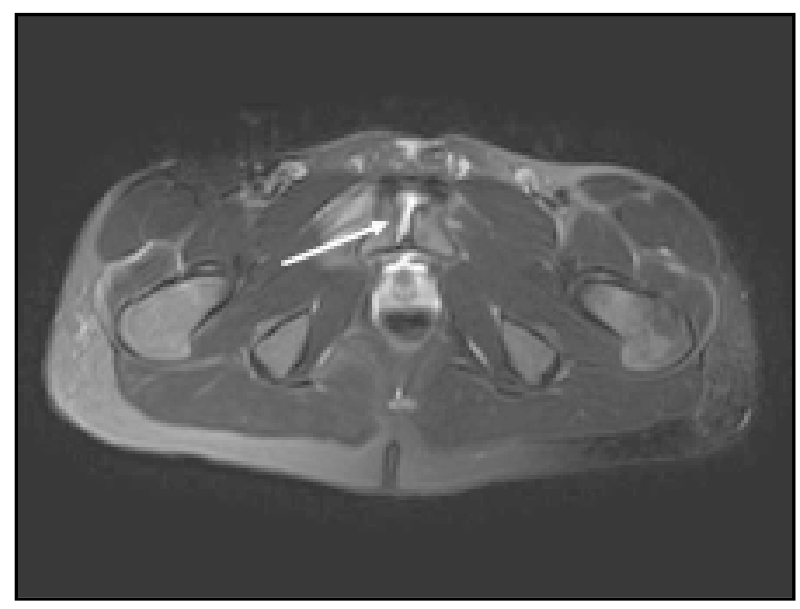

Figura 2. Corte transversal de RM T2, flecha muestra derrame y ensanchamiento de espacio articular de sínfisis del pubis.

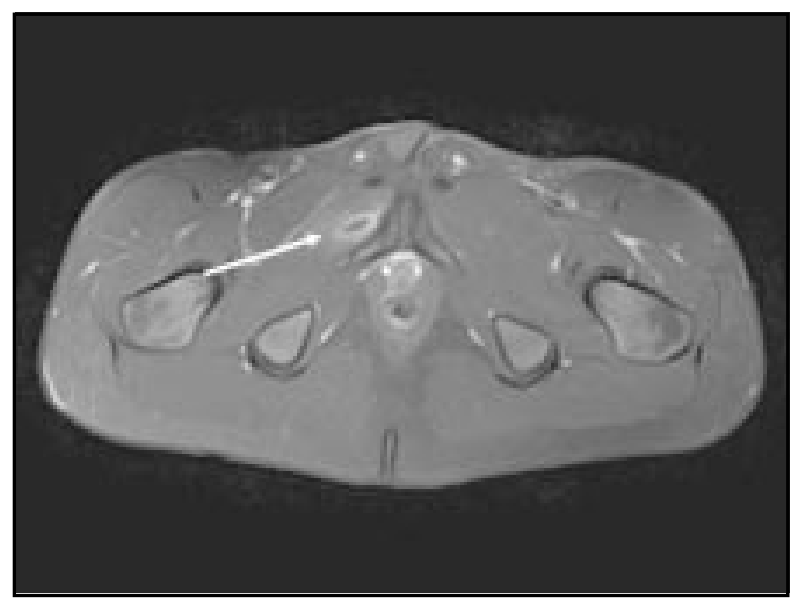

Figura 3. Corte transversal de RM T1 con Gadolinio, flecha muestra colección de 18 x $8 \mathrm{~mm}$ en músculo obturador externo derecho.

éxito en la obtención de germen en 7 de 8 colecciones sacroilíacas ${ }^{11}$. En nuestro caso, no fue posible la identificación del agente causal, ya que la lesión no era del tamaño suficiente para ser puncionada y el paciente había recibido antibióticos en forma previa, lo que afecta el rendimiento de los cultivos. Posteriormente, la buena evolución clínica del paciente con el tratamiento antibiótico empínico permitió continuar el tratamiento sin la necesidad de realizar nuevos exámenes para identificar al agente etiológico.

En la clínica destaca que el principal síntoma es el dolor, el que se ubica en la sínfisis púbica y 
Tabla 1. Factores de riesgo para artritis séptica de la sínfisis púbica

\begin{tabular}{|lc|}
\hline Factor de riesgo & Porcentaje \\
\hline Cirugía de incontinencia urinaria & 27 \\
Atletas de deportes que requiere & 19 \\
aducción de cadera & \\
Patología maligna pélvica & 17 \\
Drogadicción ev & 15 \\
Posparto & 2 \\
Cateterización cardíaca & 2 \\
Herniorrafia & 2 \\
Misceláneas & 8 \\
\hline
\end{tabular}

puede irradiarse a ingle, muslos o glúteos, aumentando con la actividad física y con la abducción de la cadera ${ }^{2,12}$. La mitad de los pacientes se presentan con marcha antiálgica 2,9 . La fiebre mayor a $38^{\circ} \mathrm{C}$ está presente en $74 \%$ de los casos y las linfoadenopatías inguinales en menos de $5 \% 9$.

Dentro de los exámenes de laboratorio, se puede encontrar alteración moderada del recuento de blancos, con elevación de PCR y VHS de forma más constante $^{9,13}$. Dentro de los exámenes de imágenes, la radiografía simple de pelvis es un examen de baja sensibilidad para el diagnóstico de la artritis séptica de la sínfisis del pubis, alrededor de $68 \%$, especialmente en estados iniciales de la enfermedad ${ }^{9,13}$. Cuando es positiva, la radiografía simple muestra márgenes

\section{REFERENCIAS}

1. Sтоскwеш RA. Articulaciones. En: Romanes G.J., ed. Cunningham Tratado de Anatomía. Duodécima edición. Madrid: Editorial Interamericana McGraw-Hill, 1987; 255.

2. Pauli S, Willemsen $\mathrm{P}$, Declerck $\mathrm{K}$, Chappel $\mathrm{R}$, VANDERVEKEN M. Osteomyelitis pubis versus osteitis pubis: a case presentation and review of the literature. Br J Sports Med 2002; 36; 71-3.

3. LENTZ SS. Osteitis pubis: a review. Obstet Gynecol Surv 1995; 50: 310-5.

4. Henderson D, St Ciair L. Osteitis pubis with five case reports. Br J Urol 1950; 22: 30-51.

5. WiLTSE LL, FRANTZ CH. Non suppurative osteitis pubis in the female. J Bone Joint Surg [Am] 1956; 38: 500-16.

6. O'Leary JA. Osteitis pubis following vesicourethral suspension. Obstet Gynecol 1964; 24: 73-7. óseos imegulares, erosión ósea y lesiones osteolíticas ${ }^{9}$.

La RM y la TC son más sensibles que la radiografía simple, mostrando cambios inflamatorios de forma más precoz. Hallazgos incluyen fluido sinfisial y edema u otras lesiones de partes blandas peripúbicas. En caso de osteomielitis, la destrucción ósea es prominente $9,11,13$.

En la ASSP, el tratamiento antibiótico debe ser iniciado lo más pronto posible, generalmente se inicia un esquema empírico que cubra los agentes etiológicos más frecuentes, considerando los factores de nesgo del paciente, ya que esto último predispone al paciente a padecer infecciones por agentes determinados $^{9}$. Se ha reportado una alta prevalencia de osteomielitis en pacientes ASSP, mayor a $95 \%$, por lo que se recomienda un tratamiento antibiótico de por lo menos 6 semanas de duración ${ }^{9,13}$. Muestras de PCR seriadas debieran tomarse para determinar la respuesta clínica al tratamiento antibiótico.

En la revisión de Ross et $\mathrm{al}^{9}, 55 \%$ de los pacientes requirió cirugía dentro del manejo de la enfermedad como complemento del tratamiento antibiótico, estableciéndose que la infección extensa y la presencia de cuerpos extraños podrían considerarse como indicaciones de cirugía.

En suma, la ASSP es una enfermedad infrecuente, que requiere de una alta sospecha clínica para realizar el diagnóstico y que la mayoría de las veces es de tratamiento médico.

7. Harth M, Bourne RB. Osteitis pubis: an unusual complication of herniorrhaphy. Can J Surg 1981; 24: 407-9.

8. Mader R, Yeromenco E. Pseudomonas Osteomyelitis of the symphysis pubis after inguinal hernia repair. Clin Rheumatol 1999; 18: 167-9.

9. Ross J, Hu L. Septic arthritis of the pubic symphysis. Medicine 2003; 82: 340-5.

10. Swan A, Amer H, Dieppe P. The value of synovial fluid assays in the diagnosis of joint disease: a literature survey. Ann Rheum Dis 2002; 61: 493-8.

11. KегтH W. Infections Arthritis. En: Terry Cnale S, ed. Campbell's Operative Orthopaedics. St Louis Missouri: Editorial Mosby, 1998: 614.

12. Gibion W, Hession P. Diseases of the pubis and pubic symphysis: MR imaging appearances. AJR 1997; 169: 849-53.

13. Lew D, WaLdVogel F. Osteomyelitis. Lancet 2004; 364: 369-79. 